\title{
Genomic losses at 5q13.2 and 8p23.1 in dysplastic hepatocytes are common events in hepatitis B virus-related hepatocellular carcinoma
}

\author{
ZHANG ZHAO $^{1 *}$, GUANG-YONG CHEN ${ }^{2 *}, \mathrm{JIANG} \mathrm{LONG}^{3}, \mathrm{HAI} \mathrm{LI}^{4}$ and JIAN HUANG ${ }^{1,5}$ \\ ${ }^{1}$ Liver Research Center and ${ }^{2}$ Department of Pathology, Beijing Friendship Hospital, Capital Medical University, \\ Beijing 100050; ${ }^{3}$ Minimally Invasive Hepatobiliary Cancer Center, Beijing You-An Hospital, Capital Medical University, \\ Beijing 100069; ${ }^{4}$ Department of Hepatopancreatobiliary and Splenic Medicine, Affiliated Hospital of \\ Medical College of Chinese People's Armed Police Force, Tianjin 300192; ${ }^{5}$ Beijing Key Laboratory of \\ Traditional Medicine in Liver Cirrhosis, National Clinical Research Center of \\ Digestive Disease, Beijing 100050, P.R. China
}

Received July 6, 2014; Accepted March 24, 2015

DOI: $10.3892 / \mathrm{ol} .2015 .3140$

\begin{abstract}
Chromosomal loci with genomic imbalances are frequently identified in hepatocellular carcinoma (HCC). Greater than two-thirds of hepatitis B virus (HBV)-related HCCs originate from liver cirrhosis following a duration of up to two decades. However, it is unclear whether these genomic imbalances occur and accumulate in dysplastic hepatocytes of the cirrhotic liver during the progression from regenerated nodules to preneoplastic lesions, including dysplastic nodules (DN). In the present study, high-grade DNs (HGDNs) of HBV-related liver cirrhosis were screened to identify loci with genomic imbalances, and the frequency of the identified loci in a group of HCCs was analyzed in order to determine whether there may be a genetic link between liver cirrhosis and HCC. Genomic DNA was extracted from six HGDNs of two cases of HBV-related liver cirrhosis and subjected to array comparative genomic hybridization (CGH) analysis with a NimbleGen $720 \mathrm{~K}$ microarray. Loci with the most frequently observed genomic imbalances in DNs were further analyzed in 83 cases of HCC by differential polymerase chain reaction (PCR) and quantitative PCR. The array $\mathrm{CGH}$ analysis revealed that the majority of genomic imbalances in the HGDNs were genomic losses of small segments, with loss of heterozygosity $(\mathrm{LOH})$ at $5 \mathrm{q} 13.2$ and 8p23.1 identified most frequently. Of the $83 \mathrm{HCC}$ cases, $30(36.1 \%)$ cases were identified with $\mathrm{LOH}$ at $5 \mathrm{q} 13.2$, where
\end{abstract}

Correspondence to: Dr Jian Huang, Liver Research Center, Beijing Friendship Hospital, Capital Medical University, 95 Yong An Road, Beijing 100050, P.R. China

E-mail: huangj1966@hotmail.com

*Contributed equally

Key words: genomic imbalances, loss of heterozygosity, 5q13.2, dysplastic nodule, hepatocellular carcinoma known tumor-associated genes are located, including general transcription factor IIH subunit $2(G T F 2 H 2)$, baculoviral IAP repeat-containing protein 1 (BIRC1) and occludin (OCLN). LOH frequency at 8p23.1 in HCC was $61.29 \%$ (D8S1130) and $68.4 \%$ (D8S503) respectively, similar to the results obtained in previous studies. In conclusion, the results of the present study provided evidence that genomic losses at 5 q13.2 and 8p23.1 identified in dysplastic hepatocytes of the cirrhotic liver are common events in HCC. HCC-associated chromosomal abnormalities may occur and accumulate in preneoplastic lesions of liver cirrhosis.

\section{Introduction}

Hepatocellular carcinoma (HCC) is one of the most common malignant neoplasms worldwide, with $\sim 50 \%$ of new cases estimated to occur in China (1). Hepatitis B virus (HBV) or hepatitis $\mathrm{C}$ virus infection, ingestion of food contaminated with aflatoxin $\mathrm{B} 1$ and alcohol consumption are considered major risk factors for HCC development (1). HBV-related HCC development progresses through three main, well-characterized stages that may occur over several decades: HBV-related chronic hepatitis, liver cirrhosis and HCC. Furthermore, over two-thirds of HCCs originate from HBV-related liver cirrhosis $(1,2)$.

Chromosomal abnormalities in HCC have been well-documented, and comparative genomic hybridization (CGH) has identified a consistent pattern of chromosomal losses and gains associated with the development and progression of HCC $(3,4)$. Furthermore, a number of studies have demonstrated characteristic chromosomal abnormalities in HCC by CGH and fluorescence in situ hybridization (FISH) (3-5). The most significant changes are partial or entire gains of chromosome arms 1q, 8q and 2q, and losses of 1p and 1q, 4q, 8p, 13q, $16 \mathrm{q}$ and $17 \mathrm{p}$. In one meta-analysis, using conventional CGH analysis with low resolution $(\sim 2 \mathrm{Mb})$ from several studies, it was revealed that the most prominent changes were gains of $1 \mathrm{q}(57.1 \%), 8 \mathrm{q}(46.6 \%), 6 \mathrm{p}(23.3 \%)$ and $17 \mathrm{q}(22.2 \%)$, and 
Table I. Clinicopathological characteristics of hepatocellular carcinoma patients.

\begin{tabular}{|c|c|c|c|}
\hline \multirow[b]{2}{*}{ Characteristics } & \multicolumn{3}{|c|}{ Informative cases } \\
\hline & $5 q 13.2$ & 8p23.1 (D8S503) & 8p23.1 (D8S1130) \\
\hline Cases, $\mathrm{n}$ & 83 & 38 & 31 \\
\hline \multicolumn{4}{|l|}{ Age, years } \\
\hline Mean & 52.1 & 52.8 & 54.1 \\
\hline Range & $30-80$ & $29-78$ & $29-78$ \\
\hline \multicolumn{4}{|l|}{ Gender, n (\%) } \\
\hline Male & $72(86.7)$ & $35(92.1)$ & $27(87.1)$ \\
\hline Female & $11(13.3)$ & $3(7.9)$ & $4(12.9)$ \\
\hline \multicolumn{4}{|c|}{ Tumor stage, n (\%) } \\
\hline 1 & $47(56.6)$ & $23(60.5)$ & $16(51.6)$ \\
\hline$>1$ & $36(43.4)$ & $15(39.5)$ & $15(48.4)$ \\
\hline \multicolumn{4}{|c|}{ HBV infection, $\mathrm{n}(\%)^{\mathrm{a}}$} \\
\hline Positive & $70(84.3)$ & $32(84.2)$ & $26(83.9)$ \\
\hline Negative & $9(10.8)$ & $4(10.5)$ & $3(9.7)$ \\
\hline \multicolumn{4}{|c|}{ Differentiation, n (\%) } \\
\hline Well & $13(15.7)$ & $7(18.4)$ & $4(12.9)$ \\
\hline Moderate & $43(51.8)$ & $19(50.0)$ & $16(51.6)$ \\
\hline Poor & $27(32.5)$ & $12(31.6)$ & $11(35.5)$ \\
\hline
\end{tabular}

${ }^{a}$ Four and two cases with hepatitis $\mathrm{C}$ virus infection not listed in the detection of loss of heterozygosity at 5q13.2 or 8p23.1, respectively. HBV, hepatitis B virus.

losses of $8 \mathrm{p}(38 \%), 16 \mathrm{q}(35.9 \%), 4 \mathrm{q}(34.3 \%), 17 \mathrm{p}(32.1 \%)$ and $13 \mathrm{q}(26.2 \%)$, and that losses of $4 \mathrm{q}, 13 \mathrm{q}$ and $16 \mathrm{q}$ were associated with $\mathrm{HBV}$ infection. Using array $\mathrm{CGH}$ analysis from four studies, it was revealed that loci with genomic gains with a prevalence of $>25 \%$ included $1 \mathrm{q}, 6 \mathrm{p}, 8 \mathrm{q}, 17 \mathrm{q}, 20 \mathrm{p}, 5 \mathrm{p} 15.33$ and $9 q 34.2-34.3$, and loci with genomic loss with prevalence of $>25 \%$ comprised 4q, 6q, 8p, 9p, 13q, 14q, 16q and 17p, and were associated with 31 classical molecular pathways, particularly the antivirus immunological pathway (6).

Since the duration of HBV-related chronic hepatitis and liver cirrhosis may be several decades (7), chromosomal abnormalities may occur and accumulate in the cirrhotic liver during the progression from regenerated nodules (RNs) to preneoplastic lesions, including dysplastic nodules (DNs), and particularly high-grade DNs (HGDNs) (8-10). However, less is known with regard to genomic imbalances associated with the progression from cirrhosis to $\mathrm{HCC}$, and the association between DNs and HCC has remained to be elucidated.

To investigate whether there is a genetic link between DNs and HCC, genomic imbalances in HGDNs were screened and analyzed by array-based CGH analysis, and the prevalence of the most frequently identified genomic imbalances in HCC was evaluated.

\section{Materials and methods}

Tumor samples. For array CGH analysis, HGDNs were collected from two male patients with HBV-related liver cirrhosis who were aged 56 and 62 years. In addition, 83 HCC cases were enrolled in the present study, in order to determine the prevalence of the identified loci in HCCs. The patients were diagnosed as follows: i) With or without HBV infection, determined by positivity or negativity for hepatitis B surface antigen; ii) tumor stage 1 or $>1$ [corresponding to TNM stage I, T1N0M0, as classified by the Union for International Cancer Control (11)]; iii) well, moderately or poorly differentiated tumors, classified according to the World Health Organization Classification of Tumors of the Digestive System (12) (Table I).

Samples were collected at the Department of Pathology, Beijing Friendship Hospital, Capital Medical University (Beijing, China) and the Minimally Invasive Hepatobiliary Cancer Center, Beijing You-An Hospital, Capital Medical University (Beijing, China), from January 2005 to April 2013. HGDNs and HCCs were examined by three pathologists and diagnosed according to the morphological criteria of RNs, DNs and HCC. Following surgical resection of HCCs and HGDNs, the samples were fixed in $4 \%$ formaldehyde and embedded in paraffin. Hematoxylin and eosin (H\&E) staining was applied to serial sections. Formaldehyde, paraffin and H\&E were purchased from Sangon Biotech (Shanghai, China).

Genomic DNA from HCCs was extracted from paraffin sections, as described previously, for conventional polymerase chain reaction (PCR) analysis (13). Extraction reagents were obtained from Sangon Biotech. In addition, 50 samples of genomic DNA were obtained from blood samples from healthy individuals at the Liver Research Center, Beijing Friendship Hospital, and used as normal controls. 
Table II. Array comparative genomic hybridization analysis of loci with genomic imbalances identified in high-grade dysplastic nodules of two hepatitis B virus-related liver cirrhosis cases.

Loci with genomic

imbalances

Position

Known harbored genes

Loss

1q21.1-21.2

$1 \mathrm{q} 32.1$

$4 \mathrm{p} 16.1$

$5 \mathrm{q} 13.2$

$6 \mathrm{p} 22.1$

$7 \mathrm{q} 11.23$

$8 \mathrm{p} 23.1$

17q21.31-21.32

22q11.21

Gain

$1 \mathrm{q} 32.1$

$11 \mathrm{q} 13.4$

$14 \mathrm{q} 24.3$

$17 \mathrm{p} 11.2$

$145902910-148120004$
$204242050-204325021$
$9009140-9351709$
$68941167-70587321$
$26819195-27108243$
$73787146-74897603$
$6907662-7903832$
$41523026-42131252$
$17086780-17299469$

199400460-199436053

78398022-78436027

77383793-77398912

16899950-16930164

\author{
FCGR1A, NBPF8, HIST2H4, et al \\ FAM72A, SRGAP2 \\ $D E F B-8, D E F B-31, \beta$-mannosyltransferase \\ GTF2H2, OCLN, NAIP, et al \\ GUSBL1, IMGL \\ GTF2I, PMS2L5, NSUN5B, et al \\ SPAG11,DEFB4, ZNF705B, et al \\ NSF, ARL17P1, NBR2, et al \\ DGCR6, PRODH, GGT2, et al
}

Titin isoform $N 2-A$

ARGEF 17

$A D C K 1$

$M R I P$
Written informed consent was obtained from all participants for the use of their clinical materials in research. The study protocol was approved by the Medical Ethics Commission of the Beijing Friendship Hospital, Capital Medical University.

Laser microdissection and DNA extraction for array CGH analysis. Serial tissue sections of $10-\mu \mathrm{m}$ thickness from each cirrhotic liver sample were placed on an ultraviolet light-absorbing membrane. HGDNs were obtained by laser microdissection using an LMD6000 (Leica Microsystems Ltd., Wetzlar, Germany). Following H\&E staining, the slides were mounted on the LMD6000 Microstat, and the selected nodules were dissected. The dissectate (with the attached specimen) fell by gravity into the caps of selected $0.5-\mathrm{ml}$ microcentrifuge tubes filled with $40 \mu \mathrm{l}$ lysate buffer and $10 \mu \mathrm{l}$ proteinase $\mathrm{K}$ (E.Z.N.A ${ }^{\circledR}$ FFPE DNA Kit, Omega Bio-Tek, Inc., Norcross, GA, USA). The tubes were subsequently incubated at $55^{\circ} \mathrm{C}$ in a water bath to allow digestion of the tissue specimens. Following overnight digestion, genomic DNA was purified according to the manufacturer's instructions and examined using a BioSpec-nano Spectrophotometer (Shimadzu Biotech, Tokyo, Japan) at a wavelength of 220-800 nm.

Array CGH. The genomic profile changes of paired DNA samples were compared using a Roche NimbleGen 720K CGH microarray (Roche NimbleGen Inc., Madison, WI, USA). Sample and gender-matched reference DNA were labeled with Cy5-dUTP and Cy3-dUTP, respectively using a NimbleGen Dual-Color DNA Labeling Kit (Roche Nimblegen Inc., Madison, WI, USA). A genomic DNA purification module was used to purify the labeled samples by precipitation with isopropanol (Sigma-Aldrich) followed by washing with $80 \%$ ice-cold ethanol (Sigma-Aldrich); these samples were then denatured at $95^{\circ} \mathrm{C}$ and applied to microarrays. Following incubation at $65^{\circ} \mathrm{C}$ for $40 \mathrm{~h}$, the microarrays were washed prior to scanning with a GenePix 4200A Scanner using GenePix 6.0 software (Molecular Devices, LLC, Sunnyvale, Ca, USA). NimbleScan v2.4 software (Roche NimbleGen) was used to normalize the raw data, which was subsequently processed using Nexus software (Nexus Copy Number ${ }^{\mathrm{TM}}$, Biodiscovery, Hawthorne, CA, USA) with default settings. The normalized data were also processed with NimbleScan software using the segMNT algorithm at the default settings (with minimum segment difference set to 0.1).

Analysis of loss of heterozygosity $(\mathrm{LOH})$ at 5q13.2. To screen for $\mathrm{LOH}$ at $5 \mathrm{q} 13.2$, differential PCR was conducted for general transcription factor IIH subunit $2(G T F 2 H 2)$, a gene located at $5 q 13.2$, with the GAPDH sequence as a reference, as described previously $(13,14)$. The primer sequences were as follows: Forward, AGCAAAGCACACCTTGAATG and reverse, ATG AATACAGCCAGGGCAAC, covering the 5' end of GTF2H2 gene $(G T F 2 H 2-1)$; forward, TAACCTAGGCGTGGGATAGG and reverse, AAGTGAAAGCCAGCCACAAC, covering the 3' end of GTF2H2 gene (GTF2H2-2); and forward, AACGTG TCAGTGGTGGACCTG and reverse, AGTGGGTGTCGC TGTTGAAGT for the GAPDH sequence (Taijixingke Biotech, Beijing, China). PCR was performed in a total volume of $20 \mu \mathrm{l}$, consisting of $2 \mu \mathrm{l}$ DNA solution (concentration, $\sim 100 \mathrm{ng} / \mu \mathrm{l}$ ), $10 \mu \mathrm{l} \mathrm{GoTaq}{ }^{\circledR}$ PCR Mix (Applied Biosystems Life Technologies, Beijing, China), and $0.8 \mu \mathrm{l}$ primer sets $(1.25 \mu \mathrm{mol} / \mathrm{l}$ of each primer), in a Veriti ${ }^{\mathrm{TM}}$ 96-Well Thermal Cycler (Applied Biosystems, Foster, CA, USA) with an initial denaturing step at $95^{\circ} \mathrm{C}$ for $5 \mathrm{~min}$ followed by 30 cycles of denaturation at $95^{\circ} \mathrm{C}$ for $50 \mathrm{sec}$, annealing at $61^{\circ} \mathrm{C}$ or $55^{\circ} \mathrm{C}$ for $60 \mathrm{sec}$, extension at $72^{\circ} \mathrm{C}$ for $60 \mathrm{sec}$, and a final extension at $72^{\circ} \mathrm{C}$ for $3 \mathrm{~min}$. Electrophoresis was performed on the PCR products on $8 \%$ acrylamide gels (Sangon Biotech), and the gels were photographed with a DC120 Zoom Digital Camera (Kodak, Rochester, NY, USA). Gel-Pro analyzer 4.0 Image Analysis 
A Chromosome 5
$\log _{2}$ ratio
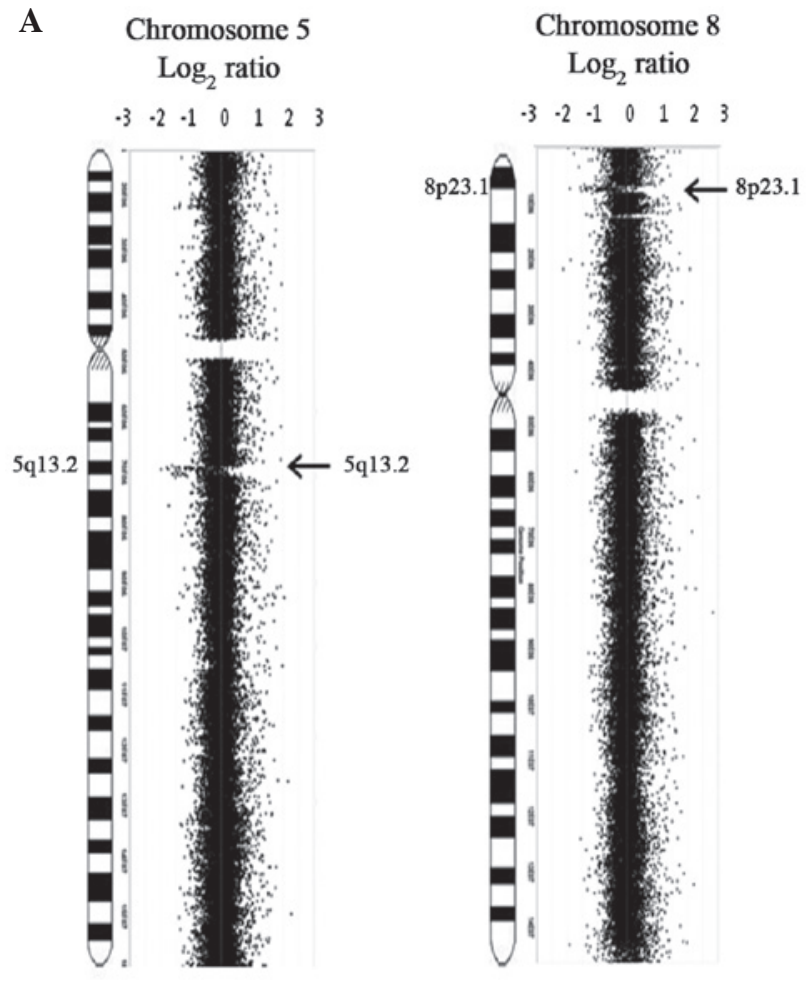

B

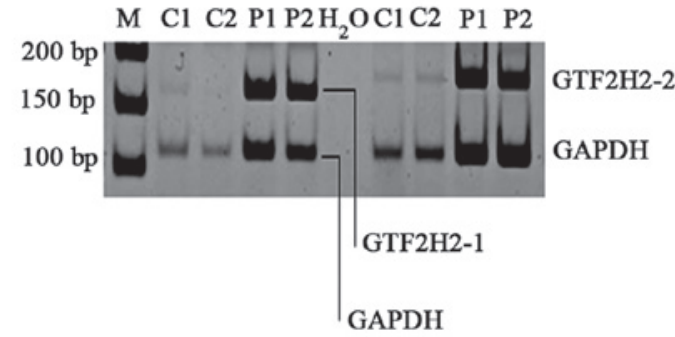

Figure 1. Loss of 5q13.2 and 8p23.1 identified in HGDNs of HBV-related liver cirrhosis. (A) Roche NimbleGen comparative genomic hybridization array analysis revealed a loss of 5q13.2 and 8p23.1 in HGDNs of HBV-related liver cirrhosis. (B) Deletion of GTF2H2 identified by differential polymerase chain reaction confirmed the loss of 5q13.2 and 8p23.1 in HGDNs of the two cases of HBV-related liver cirrhosis. GAPDH was used as a loading control. Lanes: M, 50 bp DNA ladder; C1 and C2, two cases of HBV-related liver cirrhosis; P1 and P2, normal DNA from blood; HGDN, high grade dysplastic nodules; $\mathrm{HBV}$, hepatitis B virus.

software (Media Cybernetics, Rockville, MD, USA) was used to estimate the density of each PCR fragment.

Quantitative PCR assays were performed for further confirmation of cases with $\mathrm{LOH}$ at 5q13.2. PCR was performed in a total volume of $20 \mu \mathrm{l}$, consisting of $1 \mu \mathrm{l}$ DNA solution (concentration, $\sim 100 \mathrm{ng} / \mu \mathrm{l}$ ), $10 \mu \mathrm{l} \mathrm{SYBR}{ }^{\circledR}$ Green PCR Master Mix (Applied Biosystems) and $2 \mu \mathrm{l}$ primer sets $(1.25 \mu \mathrm{mol} / \mathrm{l}$ of each primer) in a 7500 Fast PCR cycler (Applied Biosystems) with an initial denaturation step at $95^{\circ} \mathrm{C}$ for 10 min followed by 40 cycles of denaturation at $95^{\circ} \mathrm{C}$ for $50 \mathrm{sec}$, then annealing at $60^{\circ} \mathrm{C}$ for $60 \mathrm{sec}$.

Ratios of relative signal intensity of tumor tissue with that of adjacent non-tumor tissue of $<0.67$ were considered as $\mathrm{LOH}$, as described previously $(14,15)$. Five normal tissue samples obtained from Beijing You-An Hospital were used as a reference when adjacent non-tumor tissue was unavailable.
Samples demonstrating $\mathrm{LOH}$ for GTF2H2-1 and GTF2H2-2 markers were considered to have $\mathrm{LOH}$ at 5q13.2.

Analysis of LOH at 8p23.1. DNA from matched tumor and corresponding non-tumor liver tissue was analyzed for $\mathrm{LOH}$ at 8 p23.1 by amplification of two published microsatellite markers, D8S503 (forward, GGTTACGAGTTTTGTCCT TTG and reverse, GAAACAAACCAATGTAGGAGTG) and D8S1130 (forward, GAAGATTTGGCTCTGTTGGA and reverse, TGTCTTACTGCTATAGCTT), which were selected from the Genome Database (http://www.gdb.org), as described previously $(16,17)$. PCR was performed in a total volume of $25 \mu \mathrm{l}$, consisting of $2 \mu \mathrm{l}$ DNA solution (concentration, $\sim 100 \mathrm{ng} / \mu \mathrm{l}$ ), $5 \mu \mathrm{l} 5 \mathrm{X}$ Colorless GoTaq ${ }^{\circledR}$ Flexi Buffer (Applied Biosystems), $2 \mu 125 \mathrm{mM} \mathrm{MgCl}_{2}, 0.5 \mu \mathrm{l} 200 \mu \mathrm{M}$ dNTP, $0.15 \mu \mathrm{l}$ $5 \mathrm{U} / \mu 1 \mathrm{GoTaq}^{\circledR}$ Hot Start Polymerase, and $0.8 \mu \mathrm{l}$ primer sets (1.25 $\mu \mathrm{mol} / 1$ of each primer), in a Bio-Rad thermal cycler (Bio-Rad Laboratories, Inc.) using the following program: Initial denaturing step at $95^{\circ} \mathrm{C}$ for $5 \mathrm{~min}$, followed by 30 cycles of denaturation at $95^{\circ} \mathrm{C}$ for $50 \mathrm{sec}$, annealing at $59^{\circ} \mathrm{C}$ or $53^{\circ} \mathrm{C}$ for $60 \mathrm{sec}$, extension at $72^{\circ} \mathrm{C}$ for $60 \mathrm{sec}$ and a final extension at $72^{\circ} \mathrm{C}$ for $3 \mathrm{~min}$. The PCR products were subjected to electrophoresis on $8 \%$ acrylamide gels, and images of the gels were captured with a DC120 Zoom Digital Camera (Kodak). The density of each PCR fragment was estimated using Gel-Pro analyzer 4.0 Image Analysis software (Media Cybernetics Ltd., Rockville, MD, USA).

Informative visual inspection was used to determine whether the samples demonstrated LOH or no loss, or were uninformative. $\mathrm{LOH}$ was defined as a loss of intensity of $\geq 50 \%$ in one or more alleles in the tumor, compared with the identical allele in the adjacent non-tumor tissue, as described previously $(16,17)$.

Statistical analysis. The $\chi^{2}$ and Fisher's exact tests were used to determine associations between genomic imbalances and clinical parameters using 23 SAS v9.2 software (SAS Institute Inc., Cary, NC, USA). $\mathrm{P}<0.05$ was considered to indicate a statistically significant differences for all tests.

\section{Results}

Loss of 5q13.2 and 8p23.1 occur in HGDNs of HBV-related liver cirrhosis. From each case of HBV-related liver cirrhosis, three HGDNs were separated by laser microdissection and a total of six HGDNs were subjected to analysis of genomic profile changes.

Array CGH analysis revealed that genomic imbalances were randomly located in 14 chromosomal regions (Chr 1, 3, 4, 5, 7, $8,9,11,14,15,16,17,19$ and 22) in the HGDNs. These genomic imbalances were primarily identified as genomic losses of small segments, and were frequently observed at 1q21.1-21.2, 1q32.1, 4p16.1, 5q13.2, 6p22.1, 7q11.23, 8p23.1, 17q21.31-21.32 and 22q11.21, whereas genomic gains were commonly observed at 1q32.1, 11q13.4, 14q24.3 and 17p11.2 (Table II). Of these identified genomic imbalances, losses at 5q13.2 and 8p23.1 were observed most frequently (Fig. 1A). The deletion of GTF2H2 in the 5q13.2 region, as revealed by PCR analysis, confirmed $\mathrm{LOH}$ at $5 \mathrm{q} 13.2$, indicating that the results obtained by array CGH analysis were robust (Fig. 1B). In the HGDNs of one case 
Table III. Association between frequency of LOH at 5q13.2 and clinical parameters of hepatocellular carcinoma.

\begin{tabular}{|c|c|c|c|c|c|}
\hline \multirow[b]{2}{*}{ Clinical parameters } & \multirow[b]{2}{*}{ Patients, $\mathrm{n}$} & \multicolumn{2}{|c|}{ LOH 5q13.2 } & \multirow[b]{2}{*}{$\chi^{2}$-value } & \multirow[b]{2}{*}{ P-value } \\
\hline & & Cases, $\mathrm{n}$ & Percentage, $\%$ & & \\
\hline \multicolumn{6}{|l|}{ Tumor stage } \\
\hline 1 & 47 & 17 & 36.2 & 0.05 & 0.823 \\
\hline$>1$ & 36 & 13 & 36.1 & & \\
\hline \multicolumn{6}{|l|}{ HBV infection ${ }^{\mathrm{a}}$} \\
\hline Negative & 9 & 5 & 55.6 & $-{ }^{b}$ & 0.289 \\
\hline Positive & 70 & 25 & 35.7 & & \\
\hline \multicolumn{6}{|l|}{ Differentiation } \\
\hline Well or moderate & 56 & 19 & 33.9 & 0.13 & 0.718 \\
\hline Poor & 27 & 11 & 40.7 & & \\
\hline
\end{tabular}

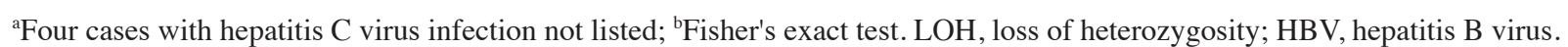

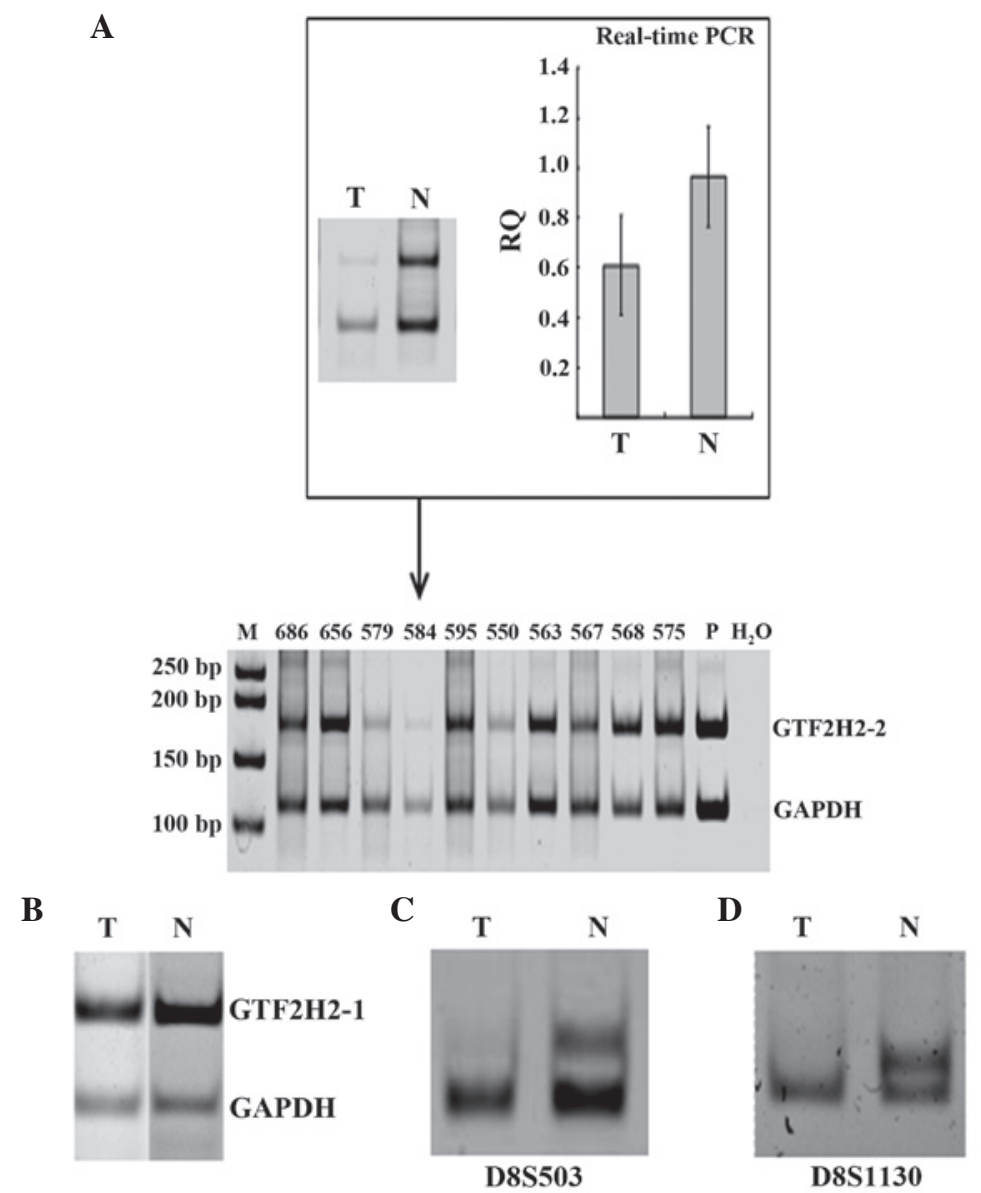

Figure 2. Analysis of prevalence of LOH at 5q13.2 and 8p23.1 in HCC. (A) Analysis of LOH at 5q13.2 using GTF2H2-2 as a marker. Differential PCR was performed on 10 HCC cases. Real-time PCR was performed on the genomic DNA of case 584, which had adjacent non-tumor tissue available, to confirm the results identified by differential PCR. Cases 550, 579 and 584 were identified as having LOH at 5q13.2. Lanes: P, normal DNA from blood; M, 50 bp DNA ladder. $\mathrm{RQ}=2^{-\delta \mathrm{CT}}$, where $\delta \mathrm{CT}=\mathrm{CT}$ (target) $-\mathrm{CT}$ (reference). Values are presented as the mean \pm standard deviation. (B) Representative results for detection of LOH 5q13.2 with GTF2H2-1 marker, in a case of HCC (case 665). (C and D) Representative results for identification of LOH at 8p23.1 in a case of HCC (case 678) showing the PCR products of the microsatellite markers (C) D8S503 and (D) D8S1130. LOH at 5q13.2 occurred predominantly in tumors (P<0.001). T, tumor; N, adjacent non-tumor tissue; PCR, polymerase chain reaction; RQ, relative quantification; $\mathrm{CT}$, threshold cycle; HCC, hepatocellular carcinoma; $\mathrm{LOH}$, loss of heterozygosity.

of HBV-related liver cirrhosis, loss of 16q22.1 was identified, a region that harbors a tumor suppressor gene, $\mathrm{CDH} 1$.
Prevalence of LOH at $5 q 13.2$ in HCC. As no microsatellite marker has previously been reported in the $5 \mathrm{q} 13.2$ region 
Table IV. Association between frequency of LOH at 8p23.1 and clinical parameters of hepatocellular carcinoma.

\begin{tabular}{|c|c|c|c|}
\hline \multicolumn{4}{|c|}{ A, LOH 8q23.1(D8S503) } \\
\hline Clinical parameters & Patients, $n(n=38)$ & Cases, n (\%) & $\mathrm{P}$-value \\
\hline Tumor stage & & & 1.000 \\
\hline 1 & 23 & $16(69.6)$ & \\
\hline$>1$ & 15 & $10(66.7)$ & \\
\hline HBV infection ${ }^{\mathrm{a}}$ & & & 1.000 \\
\hline Positive & 32 & $22(68.8)$ & \\
\hline Negative & 4 & $3(75.0)$ & \\
\hline Differentiation & & & 0.461 \\
\hline Well or moderate & 26 & $19(73.1)$ & \\
\hline Poor & 12 & $7(58.3)$ & \\
\hline
\end{tabular}

\section{B, LOH 8q23.1(D8S1130)}

\begin{tabular}{lcc}
\hline Clinical parameters & Patients, $n(n=31)$ & Cases, $n(\%)$ \\
\hline Tumor stage & 16 & \\
$\quad 1$ & 15 & $9(56.3)$ \\
$>1$ & & $10(66.7)$ \\
HBV infection ${ }^{\mathrm{a}}$ & 26 & $15(57.7)$ \\
Positive & 3 & $3(100)$ \\
$\quad$ Negative & & \\
Differentiation & 20 & $12(60.0)$ \\
$\quad$ Well or moderate & 11 & $7(63.6)$ \\
Poor & & 1.000 \\
\hline
\end{tabular}

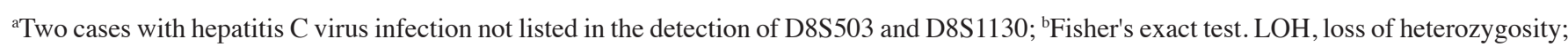
HBV, hepatitis B virus.

(position 68941167-70587321), conventional LOH analysis could not be performed. Thus, in the present study, two pairs of primers for PCR amplification of the GTF $2 \mathrm{H} 2$ gene located in this locus were used for the examination of $\mathrm{LOH}$ at $5 \mathrm{q} 13.2$, using the GAPDH gene as a control, as described in previous studies $(13,14)$. Of the $83 \mathrm{HCC}$ cases investigated, $30(36.1 \%)$ were found to have loss of $5 \mathrm{q} 13.2$ (Fig. 2A and B); this effect was not identified in any of the 50 healthy controls, indicating that $\mathrm{LOH}$ at $5 \mathrm{q} 13.2$ occurred predominantly in tumors $(\mathrm{P}<0.001)$.

Associations between the frequency of $\mathrm{LOH}$ at $5 \mathrm{q} 13.2$ and clinicopathological variables are summarized in Table III. No significant differences in the frequency of $\mathrm{LOH}$ at $5 \mathrm{q} 13.2$ were identified between distinct tumor stages, presence or absence of HBV infection, or varying degrees of tumor differentiation.

Prevalence of LOH at 8p23.1 in HCC. Two microsatellite markers, D8S503 and D8S1130, were used for the examination of $\mathrm{LOH}$ at $8 \mathrm{p} 23.1$, as described previously $(15,16)$. Of the $83 \mathrm{HCC}$ cases, 38 and 31 informative cases for D8S503 and D8S1130 were identified, respectively. Of the 38 informative D8S503 cases, 26 were identified as having LOH in D8S503 (68.4\%; Fig. 2C), while of the 31 D8S1130 cases, 19 were identified with LOH in D8S1130 (61.29\%; Fig. 2D).
Correlations between the frequency of $\mathrm{LOH}$ at $8 \mathrm{p} 23.1$ and clinicopathological variables are summarized in Table IV. No significant differences in the frequency of LOH at 8p23.1 (D8S503/D8S1130) were identified between tumor stages, presence or absence of HBV infection, or varying degrees of tumor differentiation.

\section{Discussion}

Recent studies have demonstrated that genomic loss is important in the pathogenesis of HCC. Loss of 1p, 1q, 4q, 6q, 8p, $9 \mathrm{p}, 10 \mathrm{q}, 11 \mathrm{q}, 13 \mathrm{q}, 14 \mathrm{q}, 16 \mathrm{q}, 17 \mathrm{p}$ and $22 \mathrm{q}$ have been frequently observed in HCC, and a series of tumor suppressor genes have been identified in these regions, including PRDM5 (4q26), TP53 (17p13.1), RB1 (13q14), CDH1 (16q22.1) and P33ING1DI (11q33.3-q34) $(16,18,19)$. Certain clinicopathological associations have been reported with specific abnormalities: Loss of $4 \mathrm{q}$ has been associated with enhanced $\alpha$-fetoprotein levels, TP53 mutations (20), tumor size and vascular invasion (21), while $9 p$ and $6 q$ losses have been suggested to be independent predictors of poor prognosis of HCC patients (22).

Therefore, little is known with regard to the impact of genomic imbalances in HGDNs of liver cirrhosis. 
Gong et al (23) reported that in one nodule of altered hepatocytes (NAH) with small cellular change, there were alterations in DNA copy number in four chromosomal regions. Increases in DNA copy number were often detected at 1q25.2-q21.2, 8q and 19q13.43-q13.12, whereas decreases in DNA copy number were frequently observed at $4 p, 4 q$ and 8 p. By using a microarray comprised of 2433 bacterial artificial chromosome clones to analyze 15 atypical hepatocellular neoplasms (AHN), Kakar et al (24) observed CGH abnormalities in eight (53\%) AHNs, including gains at 1q, 7p, 7q, 8p, 8q, $11 \mathrm{p}, 18 \mathrm{p}, 19 \mathrm{p}, 20 \mathrm{p}, 20 \mathrm{q}, 23 \mathrm{p}$ and 23q, and losses at 4q, 7q, 8p, $14 q, 20 q, 21 q$ and $X$. However, owing to insufficient resolution covering the human genome at $1.5 \mathrm{Mb}$, changes in small chromosomal regions cannot be detected, and it remains difficult to explore tumor-associated genes in large genomic areas. In the present study, array CGH analyses were performed with a $720 \mathrm{~K}$ array $\mathrm{CGH}$ microarray covering the human genome at $\sim 2 \mathrm{~kb}$ resolution. The results revealed that genomic imbalances identified in HGDNs of HBV-related liver cirrhosis were predominantly losses of small segments, including loss of 4p16.1, 7q11.23 and 8p23.1, as well as gain of 1q32.1, similar to the aforementioned findings in NAH or AHN $(23,24)$. Notably, certain chromosomal aberrations in the HGDNs coincided with those frequently observed in HCC, including loss of 1q21.1-21.2, 1q32.1, 8p23.1 and 22q11.21, as well as gain of 1q32.1 $(16,18,19)$. However, loss of 4q, which was frequently observed in HCC in previous studies, was not identified in the DNs of cirrhosis in the present study; this is likely to be due to the insufficient number of cases analyzed. It is notable that in one case of liver cirrhosis, the loss of 16q22.1, which is frequently observed in HCC and is associated with HBV infection, was identified in the HGDNs in the present study. Thus, consistent with other studies, the current results indicated that, as a precursor of HCC, HGDNs contain genomic imbalances associated with the pathogenesis of HBV-related HCC, and there may be genetic links between $\mathrm{DN}$ and $\mathrm{HCC}$.

LOH at $5 \mathrm{q}$ is a common chromosomal abnormality amongst tumors of the digestive system. Based on the patterns of $\mathrm{LOH}$ in all tumors in general, 11 distinct $\mathrm{Chr} 5$ regions were mapped as LOH targets, including 5p15.3, 5p15.2-p15.1, 5p14.3-p13.2, 5q13.2-q23.3, 5q14.3-q15, 5q23.1-q31.1, 5q31.3-q33.1 and 5q33.1-q33.3 (25-27). Fewer genomic imbalances at $\mathrm{Chr} 5$ in HCC have been reported, with the exception of a study by Ding et al (25), which reported that patients with non-cirrhotic HCC exhibited LOH primarily at $5 \mathrm{q}$, while patients with cirrhotic $\mathrm{HCC}$ had allelic loss at 5p. Johannsdottir et al (27) reported a high prevalence of $\mathrm{LOH}$ at 5q13.2-q23.3 in BRCA1-negative breast tumors. In addition, microdeletions at $5 \mathrm{q} 13.2$ were reported in a familial disease known as oculo-auriculo-vertebral spectrum, and a correlation between 5 q13.2 microdeletions and coarctation of the aorta was hypothesized $(28,29)$. However, to the best of our knowledge, loss at 5q13.2 in HCC has not previously been reported.

In the present study, loss at 5q13.2 was one of the most frequently observed genomic imbalances identified in HGDNs, with a prevalence of $\mathrm{LOH}$ at $5 q 13.2$ in HCCs of up to $36.1 \%$, indicating that there may be a tumor suppressor gene at this loci. The genomic loci of $5 \mathrm{q} 13.2$ encompasses the GTF2H2, NAIP, and $O C L N$ genes. GTF $2 H 2$, which encodes the transcription factor IIH, is a signaling pathway gene and was reported to be associated with the development of breast cancer (30). NAIP encodes baculoviral IAP repeat-containing protein 1 (BIRC1), which is associated with apoptosis (29). OCLN encodes occludin, which is an integral membrane protein located at tight junctions and regulates the directional migration of epithelial cells (31). However, the present study identified no significant association between the frequency of $\mathrm{LOH}$ at $5 \mathrm{q} 13.2$ and the clinical parameters of HCC. Further study is required to explore the significance of $\mathrm{LOH}$ at 5q13.2 in the development of HCC.

Previous studies have reported that a loss of $8 p$ is the most common chromosomal alteration in a variety of types of human cancer, and have postulated that one or several tumor suppressor genes may lie within this region, including PINX1 in 8p23 and DLC1 in 8p22-p21.3 (32-34). Lu et al (35) identified two sites, 8 p23.1 and 8p22, which potentially contain tumor suppressor genes involved in human liver carcinogenesis. In the present study, loss of 8p23.1 was another frequently observed locus with genomic imbalances in HGDNs, similar to the results observed in previous studies $(23,24,32)$.

The present study also evaluated the prevalence of $\mathrm{LOH}$ at 8p23.1 in HCCs, and showed its occurrence rate to be $61.29 \%$ (D8S503) or $68.4 \%$ (D8S1130) in HCCs, similar to a previous study that demonstrated the frequency of LOH at 8p23.2-21 to be $63 \%$ in HCC in a Japanese population (35). However, no significant mutation or absence of expression of the genes at 8p23.2-21 has been identified (35), and the present study also found no significant association between the frequency of $\mathrm{LOH}$ at 8p23.1 and the clinicopathological characteristics of HCC. Although no significant genetic alterations were detected in $\mathrm{HCC}$ at $8 \mathrm{p} 23.1$, the results of the present study suggest that unknown genes in this region may be significant in HCC, as suggested by a previous study (35). Further studies are required to explore the significance of $\mathrm{LOH}$ at 8p23.1 in the development of HCC.

Although array CGH array analysis was only performed on a small set of HGDNs, the present study demonstrated that, as precursors of HCC, HGDNs contain genomic imbalances associated with HCC pathogenesis, suggesting that chromosomal abnormalities may occur and accumulate in preneoplastic lesions of liver cirrhosis. Further studies are required to screen loci with genomic imbalances in HGDNs in a greater number of cases, and to identify the critical tumor suppressor genes in these loci to elucidate their roles in the development of HCC from liver cirrhosis.

\section{Acknowledgements}

The authors would like to thank Dr Xiao-Yan Shi (Department of Pathology, Beijing Friendship Hospital, Capital Medical University) for his critical pathological review. This work was supported by grants from the Wang Bao-En Liver Fibrosis Foundation (grant no. 20100013), the Scientific Research Foundation for Returned Overseas Chinese Scholars, State Education Ministry (2011, No. 41) and a returning grant from the International Agency for Research on Cancer (IARC, FEL/09/03). The Abstract from the present study was presented as a poster in the 65th Annual Meeting of the American Association for the Study of Liver Diseases: The Liver Meeting 2014. 


\section{References}

1. Theise ND, Chen CJ and Kew MC: Liver cancer. In: World Cancer Report 2014. Stewart B and Wild C (eds). International Agency for Research on Cancer, Lyon, pp577-593, 2014.

2. Hsu YS, Chien RN, Yeh CT, et al: Long-term outcome after spontaneous $\mathrm{HBeAg}$ seroconversion in patients with chronic hepatitis $\mathrm{B}$ Hepatology 35: 1522-1527, 2002.

3. Kim TM, Yim SH, Shin SH, et al: Clinical implication of recurrent copy number alterations in hepatocellular carcinoma and putative oncogenes in recurrent gains on 1q. Int J Cancer 123: 2808-2815, 2008.

4. Patil MA, Gütgemann I, Zhang J, et al: Array-based comparative genomic hybridization reveals recurrent chromosomal aberrations and Jab1 as a potential target for 8q gain in hepatocellular carcinoma. Carcinogenesis 26: 2050-2057, 2005.

5. Midorikawa Y, Tang W and Sugiyama Y: High-resolution mapping of copy number aberrations and identification of target genes in hepatocellular carcinoma. Biosci Trends 1: 26-32, 2007.

6. Guo X, Yanna, Ma X, et al: A meta-analysis of array-CGH studies implicates antiviral immunity pathways in the development of hepatocellular carcinoma. PLoS One 6: e28404, 2011.

7. Han ZG: Recent progress in genomic research of liver cancer. Sci China C Life Sci 52: 24 30, 2009.

8. International Consensus Group for Hepatocellular Neoplasia: Pathologic diagnosis of early hepatocellular carcinoma: A report of the international consensus group for hepatocellular neoplasia. Hepatology 49: 658-664, 2009.

9. International Working Party: Terminology of nodular hepatocellular lesions. Hepatology 22: 983-993, 1995.

10. Di Tommaso L, Sangiovanni A, Borzio M, et al: Advanced precancerous lesions in the liver. Best Pract Res Clin Gastroenterol 27: 269-284, 2013.

11. Sobin LH and Wittekind CH (eds): TNM Classification of Malignant Tumours. 6th edition. Wiley, New York, NY, pp81-83, 2002.

12. Theise ND, Curado MP, Franceschi S, et al: Hepatocellular carcinoma. In: WHO Classification of Tumors of the Digestive System. Bosman FT, Carneiro F, Hruban RH and Theise ND (eds). International Agency for Research on Cancer, Lyon, pp205-216, 2010.

13. Huang J, Grotzer MA, Watanabe T, et al: Mutations in the Nijmegen breakage syndrome gene in medulloblastomas. Clin Cancer Res 14 4053-4058, 2008.

14. Huang J, Pang J, Watanabe T, Ng HK and Ohgaki H: Whole genome amplification for array comparative genomic hybridization using DNA extracted from formalin-fixed, paraffin-embedded histological sections. J Mol Diagn 11: 109-116, 2009.

15. Sun FY, Wan DF, Qing WX, et al: Determination of gene deletion in tumor tissue by semi-quantitative polymerase chain reaction. Tumor 20: 135-137, 2000 (In Chinese).

16. Tomlinson IP, Lambros MB and Roylance RR: Loss of heterozygosity analysis: Practically and conceptually flawed? Genes Chromosomes Cancer 34: 349-353, 2002.

17. Zhou HL, Gong L, Zhang W, Du YX, Zhang JY and Feng YM: Loss of heterozygosity on chromosomes 8 and 16 in primary hepatocellular carcinoma. Xian Dai Zhong Liu Yi Xue 20: 1134-1138, 2012 (In Chinese).

18. Lau SH and Guan XY: Cytogenetic and molecular genetic alterations in hepatocellular carcinoma. Acta Pharmacol Sin 26: 659-665, 2005.
19. Niketeghad F, Decker HJ, Caselmann WH, et al: Frequent genomic imbalances suggest commonly altered tumour genes in human hepatocarcinogenesis. Br J Cancer 85: 697-704, 2001.

20. Rashid A, Wang JS, Qian GS, Lu BX, Hamilton SR and Groopman JD: Genetic alterations in hepatocellular carcinomas: association between loss of chromosome 4q and p53 gene mutations. Br J Cancer 80: 59-66, 1999.

21. Zondervan PE, Wink J, Alers JC, et al: Molecular cytogenetic evaluation of virus-associated and non-viral hepatocellular carcinoma: analysis of 26 carcinomas and 12 concurrent dysplasias. J Pathol 192: 207-215, 2000.

22. Laurent-Puig P, Legoix P, Bluteau O, et al: Genetic alterations associated with hepatocellular carcinomas define distinct pathways of hepatocarcinogenesis. Gastroenterology 120: 1763-1773, 2001.

23. Gong L, Li YH, Su Q, Chu X and Zhang W: Clonality of nodular lesions in liver cirrhosis and chromosomal abnormalities in monoclonal nodules of altered hepatocytes. Histopathology 56 : 589-599, 2010.

24. Kakar S, Chen X, Ho C, et al: Chromosomal abnormalities determined by comparative genomic hybridization are helpful in the diagnosis of atypical hepatocellular neoplasms. Histopathology 55: 197-205, 2009.

25. Zhang F, Zhou C, Ling Y, et al: Allelic analysis on chromosome 5 in sporadic colorectal cancer patients. Zhonghua Zhong Liu Za Zhi 24: 458-460, 2002 (In Chinese).

26. Ding SF, Habib NA, Dooley J, et al: Loss of constitutional heterozygosity on chromosome $5 \mathrm{q}$ in hepatocellular carcinoma without cirrhosis. Br J Cancer 64: 1083-1087, 1991.

27. Johannsdottir HK, Jonsson G, Johannesdottir G, et al: Chromosome 5 imbalance mapping in breast tumors from BRCA1 and BRCA2 mutation carriers and sporadic breast tumors. Int J Cancer 119: 1052-1060, 2006.

28. Huang XS, Xiao L, Li X, et al: Two neighboring microdeletions of 5 q13.2 in a child with oculo-auriculo-vertebral spectrum. Eur J Med Genet 53: 153-158, 2010.

29. Chen CP, Lin CJ, Chen CY, et al: Maternal transmission of interstitial microdeletion in 5q13.2 detected during prenatal diagnosis of coarctation of the aorta. Taiwan J Obstet Gynecol 52: 303-305, 2013.

30. Markaverich BM, Shoulars K and Rodriquez MA: Luteolin regulation of estrogen signaling and cell cycle pathway genes in MCF-7 human breast cancer cells. Int J Biomed Sci 7: 101-111, 2011.

31. Du D, Xu F, Yu L, Zhang C, Lu X, Yuan H, et al: The tight junction protein, occludin, regulates the directional migration of epithelial cells. Dev Cell 18: 52-63, 2010

32. Kahng YS, Lee YS, Kim BK, Park WS, Lee JY and Kang CS: Loss of heterozygosity of chromosome 8p and $11 \mathrm{p}$ in the dysplastic nodule and hepatocellular carcinoma. J Gastroenterol Hepatol 18: 430-436, 2003.

33. Chan KL, Lee JM, Guan XY, Fan ST and Ng IO: High-density allelotyping of chromosome 8p in hepatocellular carcinoma and clinicopathologic correlation. Cancer 94: 3179-3185, 2002.

34. Pineau P, Nagai $\mathrm{H}$, Prigent $\mathrm{S}$, et al: Identification of three distinct regions of allelic deletions on the short arm of chromosome 8 in hepatocellular carcinoma. Oncogene 18: 3127-3134, 1999.

35. Lu T, Hano H, Meng C, et al: Frequent loss of heterozygosity in two distinct regions, 8p23.1 and 8p22, in hepatocellular carcinoma. World J Gastroenterol 13: 1090-1097, 2007. 